Missed Diagnosis

\title{
Primary tumours of the duodenum
}

\author{
Naftali Kaminski, Dorit Shaham ${ }^{1}$ and Rami Eliakim
}

Department of Medicine and ${ }^{1}$ Radiology, Hadassah University Hospital, Mount Scopus, PO Box 24035, Jerusalem 91240, Israel

\begin{abstract}
Summary: Six primary duodenal tumours were diagnosed in our 300 bed institute during a period of 10 years. Two patients had benign tumours (leiomyoma and carcinoid) and four had malignant tumours (adenocarcinoma). The most common manifestation was severe iron deficiency anaemia. Diagnosis was usually delayed (with a mean time of 7.7 months from initial complaints), endoscopy being the most common and useful diagnostic tool. A curative procedure was performed in two patients. Patients with unexplained chronic iron deficiency anaemia should undergo thorough gastrointestinal evaluation, including the small intestine, as a curable disease may be found to be the source of the complaint.
\end{abstract}

\section{Introduction}

Tumours of the small intestine are rare. ${ }^{1}$ Although the small intestine accounts for at least $75 \%$ of the total length of the gastrointestinal (GI) tract, its tumours represent about $5 \%$ of all alimentary tract neoplasms. The duodenum, which constitutes only $4 \%$ of small intestinal length, incorporates a relatively high proportion of all the tumours. ${ }^{2,3} \mathrm{~A}$ duodenal carcinoma was first documented in $1746 .{ }^{4}$

Adenoma is the most common benign neoplasm of the small intestine $(30 \%)$, leiomyomas and lipomas being almost as common $(22 \%$ and $20 \%$, respectively). ${ }^{5}$ Of the malignant tumours, adenocarcinoma is the most common, constituting about $80 \%$ of the malignant tumours in most reported series. ${ }^{1,6}$ Duodenal carcinomas account for $20-$ $25 \%$ of all small bowel malignancies, sarcoma, carcinoid and lymphoma being less common (7, 5 and $3 \%$, respectively). ${ }^{7}$

The present report describes six cases of primary duodenal neoplasms seen at Hadassah University Hospital in the last 10 years and refers to the specific clinical problems encountered.

\section{Methods}

The charts of patients suffering from either benign or malignant tumours of the duodenum and hospitalized at Hadassah University Hospital in the years 1980-1990 were evaluated. Patients with periampullary tumours were excluded. The charts were evaluated for age, sex, initial clinical presenta-

Correspondence: N. Kaminski, M.D.

Accepted: 2 July 1992 tion, the time from initial complaints to diagnosis, the method of diagnosis, the type of tumour found and the treatment given.

\section{Results}

Six patients, three males and three females, were found to have either benign (two patients) or malignant (four patients) tumours of the duodenum. The mean age was 60.6 years, ranging from 47 to 77 years (Table I). The initial presentation in all cases included either severe iron deficiency anaemia or acute gastrointestinal bleeding. Two patients suffered from abdominal pain and weight loss $(33 \%)$. Two others were referred due to extreme weakness, palpitations and shortness of breath. Three patients had undergone thorough small and large bowel examinations, the tests yielding negative results.

Endoscopy established the diagnosis in five out of the six patients. The two benign tumours underwent local resection. Whipple's procedure was performed in two of the four patients with adenocarcinoma.

\section{Discussion}

The clinical presentation of duodenal tumours is nonspecific and insidious. Benign tumours of the small intestine may go undiagnosed and symptomless in as many as $60 \%$ of cases and are detected only at autopsy. The most common symptom is pain, most often releated to obstruction of a partial or intermittent nature. Proximal lesions may pre- 
Table I Clinical data and modes of diagnosis in patients with tumours of the duodenum

\begin{tabular}{|c|c|c|c|c|c|c|}
\hline Case & Age & $\operatorname{Sex}$ & Clinical presentation & $\begin{array}{l}\text { Time from initial } \\
\text { complaints to diagnosis }\end{array}$ & $\begin{array}{l}\text { Method of } \\
\text { diagnosis }\end{array}$ & Histology \\
\hline 1 & 77 & $\mathbf{F}$ & $\begin{array}{l}\text { Severe iron deficiency } \\
\text { anaemia, weakness }\end{array}$ & 2 years & UGI + passage & Leiomyoma \\
\hline 2 & 64 & $\mathbf{M}$ & $\begin{array}{l}\text { Severe iron deficiency } \\
\text { anaemia, weakness }\end{array}$ & 2 months & Endoscopy & Carcinoid \\
\hline 3 & 47 & $\mathbf{F}$ & $\begin{array}{l}\text { Severe iron deficiency } \\
\text { anaemia, weakness, } \\
\text { epigastric pain }\end{array}$ & 8 months & Endoscopy & Adenocarcinoma $^{*}$ \\
\hline 4 & 61 & $\mathbf{M}$ & Weight loss, melaena & 6 months & Endoscopy & Adenocarcinoma \\
\hline 5 & 65 & $\mathbf{F}$ & $\begin{array}{l}\text { Severe iron deficiency } \\
\text { anaemia, weakness, } \\
\text { weight loss }\end{array}$ & 6 months & $\begin{array}{l}\text { UGI + passage, } \\
\text { endoscopy }\end{array}$ & Adenocarcinoma $^{*}$ \\
\hline 6 & 50 & $\mathbf{M}$ & $\begin{array}{l}\text { Epigastric pain, } \\
\text { melaena }\end{array}$ & 2 weeks & Endoscopy & Adenocarcinoma \\
\hline
\end{tabular}

*Denotes resectable tumours in patients who underwent Whipple's procedure.

sent as gastric outlet obstruction. ${ }^{1,8}$ Bleeding, occult or overt ${ }^{2,8,9}$ is the second most common symptom (20-50\%). The two patients with benign tumours in our series (Nos 1 and 2, Table I) were referred due to severe iron deficiency anaemia, without abdominal pain. Most malignant tumours eventually produce acute or chronic symptoms. Acute symptoms, including melaena, massive haemorrhage, obstruction or perforation, are common. ${ }^{5,9}$ These symptoms were not observed in most of our patients. Chronic symptoms, including anaemia, weight loss and abdominal pain, ${ }^{7}$ often lead to evaluation of the upper and lower gastrointestinal tract. The small bowel is overlooked, as was the case in most of our patients. The interval between the initial complaints and diagnosis may be delayed as long as 18 months; the mean time in our patients was 8 months.

The diagnostic problem posed by duodenal tumours is complicated by their rarity, nonspecific signs and symptoms, and by the fact that the distal portions of the duodenum are generally overlooked during upper GI endoscopy. In none of our patients was a duodenal tumour considered the primary cause of the complaints. Retrospectively such tumours have been found in $60-90 \%$ of upper GI barium series, ${ }^{10}$ although correct diagnosis was made in only $20-50 \%$ of symptomatic patients. ${ }^{11}$ In our study $50 \%$ of the patients had undergone negative bowel examinations before coming to our attention. In one of our symptomatic patients (No. 4, Table I) the diagnosis was evident after an upper GI barium series (Figure 1) had been performed. Upper GI endoscopy is the main diagnostic tool, ${ }^{12,13}$ and was used to establish the diagnosis in five of our six patients. Computerized tomographic scanning of the abdomen is useful, especially in detecting extraluminal tumours, such as leiomyomas or metastatic spread. None of our cases was diagnosed by computerized tomographic scanning, although it was used for evaluating the extent of metastatic involvement.

To date, there is no treatment other than surgery, for primary duodenal tumours, provided there are no metastases and the tumour is resectable. The

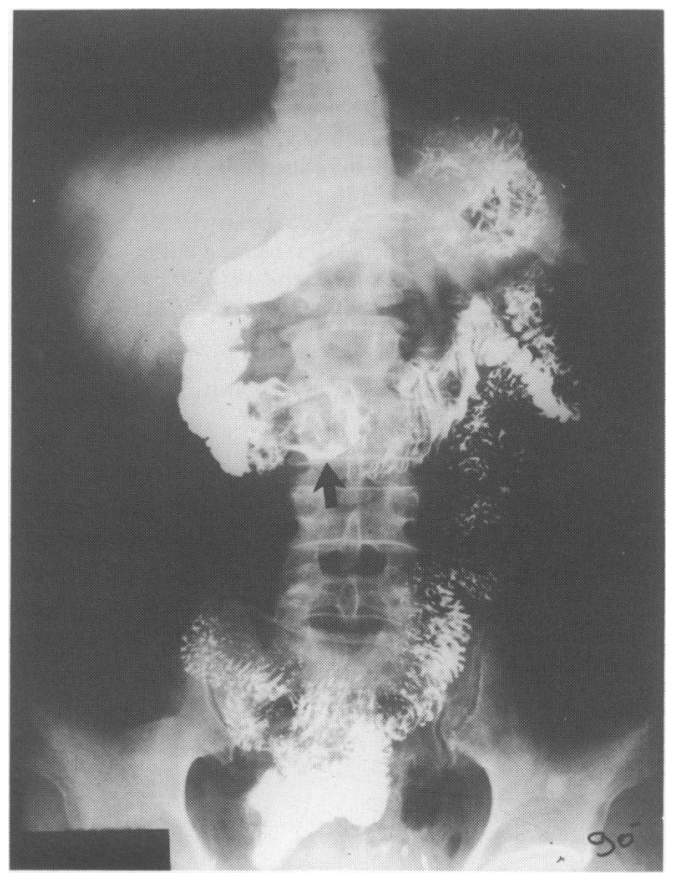

Figure 1 Adenocarcinoma of the duodenum presenting as a large filling defect in the second portion of the duodenum (arrow). 
only exception to this rule might be lymphoma of the small intestine in which chemotherapy may prove feasible. If the lesion is in the third or fourth portion of the duodenum, segmental resection is indicated. ${ }^{14}$ In most malignant tumours, pancreaticoduodenectomy (Whipple's procedure) is performed, if a curative procedure is indicated. The operative mortality in Whipple's procedure is $3-21 \% .^{15,16}$ The 5 year survival rate in patients with adenocarcinoma of the duodenum is $10-20 \%$; in cases of nonresectable tumours most patients die within the first year. ${ }^{14,15,17}$ These survival rates should not be considered absolute figures, as the number of patients reported in the literature is quite small. Of our patients with malignant tumours, two underwent curative procedures and one is alive and doing well 18 months following surgery.

\section{References}

1. Weiss, N.S. \& Yang, C. Incidence of histologic types of cancer of the small intestine. $J$ Natl Cancer Inst 1987, 78: 653-656.

2. Rochlin, D.B. \& Longmire, W.P., Jr. Primary tumors of the small intestine. Surgery 1961, 50: 586-592.

3. Darling, R.C. \& Welch, C.E. Tumors of the small intestine. $N$ Engl J Med 1959, 260: 397-408.

4. Hamburger, G. De Ruptura Intestine Duodeni. Jean Ritterianis, 1746.

5. Ashley, W.S. \& Wells, S.A. Jr. Tumors of the small intestine. Semin Oncol 1988, 15: 116-128.

6. Bruno, M.S. \& Fein, H.D. Primary malignant and benign tumors of the duodenum. Arch Intern Med 1970, 126: 670-679.

7. Richard, M.G. Malignant tumors of the small intestine. Surg Clin North Am 1986, 66: 779-785.

8. Ollinger, R.M., Jr, Sternfeld, W.C. \& Schreiber, H. Primary neoplasms of the small intestine. Am J Surg 1986, 151: 654-658.

9. Sharon, P., Stalnikovicz, R. \& Rachmilewitz, D. Endoscopic diagnosis of duodenal neoplasms causing upper gastrointestinal bleeding. J Clin Gastroenterol 1982, 4: 35-38.

10. Good, C.A. Tumors of the small intestine: Caldwell lecture. $A J R$ 1963, 89: 685-692.

\section{Conclusions}

The six cases described represent typical problems encountered in patients with duodenal tumours, the difficulty and lag in establishing diagnosis due to the relative rarity and inaccessibility of these tumours, the lack of a simple curative procedure and the grave prognosis.

The nonspecific signs and symptoms of these tumours should prompt physicians to carry out thorough examinations of patients presenting with anaemia, weakness and abdominal pain. It is recommended that the entire gastrointestinal tract, including the small intestine, of patients with unexplained pain with or without iron deficiency anaemia, be explored. Alertness and thorough investigation may expedite diagnosis and increase the changes of the patient's survival.

11. Ostermiller, W., Joergenson, E.C. \& Weioe, L. A clinical review of tumors of the small bowel. Am J Surg 1966, 11: 403-409.

12. Maimon, H.N., Grady, P.G. \& Milligan, F.D. Endoscopic diagnosis of duodenal neoplasms. Hopkins Med J 1973, 132: 206-211.

13. Wald, A. \& Milligan, F.D. The role of fiberoptic endoscopy i the diagnosis and management of duodenal neoplasm. Am Dig Dis 1975, 20: 499-505.

14. Alwmark, A., Andersson, A. \& Lasson, A. Primary cafō cinoma of the duodenum. Ann Surg 1980, 191: 13-18.

15. Michelassi, F., Erroi, F., Dawson, P.J. et al. Experience with 647 consecutive tumors of the duodenum, ampulla, head of pancreas, and distal common bile duct. Ann Surg 1989, 210: $544-556$.

16. Trede, M. \& Schwall, G. The complication of pancreatectomy. Ann Surg 1988, 207: 39-47.

17. Jowsting, D.R., Peart, R.W., Jr, Van Heerden, J.A. \& Weiland, L.H. Improving survival in adenocarcinoma of the duodenum. Am J Surg 1981, 144: 228-231. 